\title{
Textos variantes de comedias de Calderón en testimonios no fiables: Las manos blancas no ofenden*
}

\author{
Variant texts of Calderón's plays in unreliable editions: \\ Las manos blancas no ofenden
}

Fernando Rodríguez-Gallego

Universitat de les Illes Balears/ Institut d'Estudis Hispànics en la Modernitat f.rodriguez-gallego@uib.cat ORCID iD: http://orcid.org/0000-0002-6539-0447

\begin{abstract}
RESUMEN: En este artículo se traza un estado de la cuestión de la auto-reescritura de comedias de Calderón de la Barca, atendiendo a los tipos de testimonios en que se han conservado los diferentes textos y prestando particular atención a aquellos casos en que ninguno de los testimonios cuenta con el aval del propio Calderón. Los problemas derivados de esta situación se ejemplifican a partir de la comedia Las manos blancas no ofenden.
\end{abstract}

Palabras clave: Calderón de la Barca, auto-reescritura, crítica textual, Las manos blancas no ofenden.

ABSTRACT: This article outlines the state of the question regarding Calderón's re-writing of his own plays, with attention to the kind of version in which the different texts have been preserved, and focusing on those cases in which none of the editions has been supervised in any sense by Calderón. The problems aris-

\footnotetext{
* Como colaborador externo del Grupo de Investigación Calderón que dirige Luis Iglesias Feijoo en la Universidad de Santiago de Compostela, el artículo se incluye en los siguientes proyectos de investigación: DGICYT FFI2012-38956 (investigador principal: Luis Iglesias Feijoo) y "Patrimonio Teatral clásico español. Textos e instrumentos de investigación (TECE-TEI)" (proyecto Consolider CSD2009-00033; coordinador general: Joan Oleza), y se acoge a una "Axuda do Programa de consolidación e estructuración de Unidades de Investigación competitivas" (GPC2013/027) de la Xunta de Galicia, que recibe fondos Feder.
} 
ing from this situation are exemplified in the textual transmission of the play Las manos blancas no ofenden.

Keywords: Calderón de la Barca, self-rewriting, textual criticism, Las manos blancas no ofenden.

En los últimos treinta años, aproximadamente, se ha incrementado en gran medida el número y rigor de las ediciones críticas de obras teatrales del Siglo de Oro, lo que ha permitido comprobar que los textos que se solían manejar, como los de las Obras completas de Calderón en Aguilar (Rodríguez-Gallego, 2015) o los de la edición de la Academia, en el caso de Lope, por ejemplo, estaban lejos, en muchas ocasiones, de ser los mejores posibles. La atención prestada a ediciones y manuscritos que se habían mantenido olvidados durante años, además de permitir leer las comedias áureas en textos más acreditados, puso también a veces de relieve la existencia de textos con variaciones que podían afectar a un número muy elevado de los versos de una comedia, fenómeno que afecta particularmente a Calderón de la Barca, quien, de acuerdo con Marc Vitse (1998: 6), "es, por antonomasia, el dramaturgo áureo de la reescritura".

Aunque ya existían algunos trabajos anteriores pioneros, el estudio de diferentes casos de reescritura referidos tanto a comedias como a autos sacramentales de Calderón experimentó un considerable auge también en estos últimos treinta años, en especial desde la constatación de que el fenómeno afectaba a algunas de las comedias mayores de don Pedro, como La dama duende, El mayor monstruo del mundo o, en especial, La vida es sueño ${ }^{1}$. Vistos ahora estos procesos de reescritura con una cierta perspectiva, se pueden poner de relieve algunos de los problemas más importantes que nos encontramos a la hora de estudiarlos, que tienen que ver, en primer lugar, con la fiabilidad de los textos que han transmitido las versiones de una determinada comedia.

La situación ideal sería aquella en la que conservamos dos manuscritos autógrafos de una misma pieza en los que se recogen dos versiones diferentes de esta, o bien un solo manuscrito autógrafo u otro texto en el que el dramaturgo de su puño y letra revisa y reescribe diferentes pasajes de una obra, dando lugar a una nueva versión de esta.

Sin embargo, tal situación ideal solo se da raras veces. En el caso de Calderón sucede en el auto sacramental El diablo mudo, cuya segunda versión se conserva en un autógrafo en el que Calderón, en ocasiones, después de copiar el texto de la primera versión que se ha conservado en otros testimonios, decide

\footnotetext{
${ }^{1}$ Puede verse el estado de la cuestión de Rodríguez-Gallego (2010).
} 
tacharlo para escribir en el margen una nueva versión (Calderón de la Barca, 1999: 59-60). A su vez, en el autógrafo de la comedia La desdicha de la voz Calderón reescribe, siempre de su puño y letra, varios pasajes, y suprime otros, lo que origina la existencia de dos versiones de algunas escenas (Calderón de la Barca, 2003: 3-14), como también sucede, aunque en menor extensión, en el autógrafo de El secreto a voces, en el que Calderón atajó de su mano diferentes pasajes dando lugar a una versión más corta que coexiste junto a una más larga (Kroll, 2014; Calderón de la Barca, 2015). En lo que respecta a Cada uno para sí, en el manuscrito 16887 de la BNE, parcialmente autógrafo, se conservan dos versiones de la tercera jornada, con varios folios de puño y letra de Calderón que reescriben diferentes pasajes con el probable fin de intentar recuperar la versión original de la jornada, corrupta e incompleta en la edición de la comedia publicada en la Parte 15 de Escogidas (Madrid, 1661). En el mencionado manuscrito se conservan incluso los borradores de algunos de estos pasajes, también de puño y letra de Calderón (Calderón de la Barca, 1982: 3-28 y 38-82; Casariego Castiñeira, 2015).

Para el resto de los procesos de reescritura que se han analizado hasta la fecha se dan básicamente tres diferentes tipos de situaciones:

1. Aquellas en las que los dos textos están autorizados ${ }^{2}$, aunque no sean autógrafos.

2. Aquellas en las que solo uno de los textos está autorizado, sea o no un autógrafo.

3. Aquellas en las que ninguno de los textos está autorizado.

Entre las comedias de Calderón estudiadas hasta la fecha de las que se haya defendido la existencia de dos versiones ${ }^{3}$, solo en una los dos testimonios principales están de alguna manera autorizados: El mayor monstruo del mundo, cuya primera versión fue publicada en 1637 en la Segunda parte de Calderón, preparada nominalmente por el hermano del dramaturgo y cuyo privilegio fue concedido al propio poeta, en tanto que la segunda se conserva en el manuscrito parcialmente autógrafo Res.-79 de la Biblioteca Nacional, muy posterior a la parte (cuenta con censuras de 1667 y 1672). Sin embargo, y a pesar de la aparente fiabilidad de ambos testimonios, Ruano de la Haza (1998) puso en duda que se trate de dos versiones plenamente autoriales, pues defendió que la pri-

\footnotetext{
${ }^{2}$ Por textos autorizados entiendo, bien manuscritos autógrafos o parcialmente autógrafos, bien manuscritos que conste que fueron copiados bajo la supervisión de Calderón o con el visto bueno de este, bien ediciones en cuya preparación Calderón participó de alguna manera, como las partes Primera y Segunda o la edición de los autos de 1677, aunque quizá puedan incluirse también, de manera más dudosa, las partes Tercera y, con algo más de fundamento, Cuarta.

${ }^{3}$ En este artículo solo tendremos en cuenta reescrituras que afecten a la totalidad de una comedia, o al menos a una jornada, por lo que no se recogen aquí casos como los estudiados por Margaret Greer (1984) en un artículo sobre reescritura en los finales de comedias.
} 
mera de ellas derivaría de un texto malamente reelaborado por un autor de comedias, postura que ha sido discutida por María Caamaño (2001 y 2002; Calderón de la Barca, 2017).

El segundo de los supuestos, aquel en el que solo una de las versiones se conserva en un texto autorizado, es el mayoritario, al menos entre los casos que se han puesto de relieve hasta hoy. En cuatro comedias, El agua mansa, El mágico prodigioso, Cada uno para sí y Basta callar, el texto autorizado es nada menos que un autógrafo, completo, en el caso de las dos primeras ${ }^{4}$, o parcial, en el de las dos últimas $^{5}$. En otras siete obras, el texto autorizado se publicó en las partes Primera (1636) o Segunda (1637) de Calderón, las preparadas nominalmente por un hermano del dramaturgo, José, y con privilegio a nombre del propio Pedro. Se trata de La dama duende, Casa con dos puertas mala es de guardar, La vida es sueño, La devoción de la cruz y El príncipe constante (en la Primera parte) y de Judas Macabeo y El astrólogo fingido (en la Segunda). Otros tres casos (El laurel de Apolo, La púrpura de la rosa y El conde Lucanor) pueden incluirse en este grupo pero de manera más cauta, ya que el texto autorizado fue publicado en las partes Tercera - las dos primeras - o Cuarta - El conde Lucanor-, que contaron al menos con un cierto visto bueno del dramaturgo — que incluso solicitó el privilegio de la Cuarta-, aunque la participación de este en ellas se discuta, en particular en lo que se refiere a las dos ediciones de la Cuarta $^{6}$.

El hecho de que contemos con al menos un texto autorizado no tiende necesariamente a facilitar las cosas, ya que no podemos saber a priori si la versión del texto no autorizado se debe a la participación de Calderón, por lo que estaríamos ante un caso de autorreescritura, o bien a la de alguna otra persona del mundo teatral, habitualmente un autor de comedias, con lo que estaríamos ante un ejemplo de heterorreescritura. Esto último es lo que parece haber sucedido con El príncipe constante (Hernando Morata, 2012), Basta callar (Calderón de la Barca, 1995a y 2000) o El conde Lucanor $^{7}$, o quizá sucediera en el discutido

\footnotetext{
${ }^{4}$ El autógrafo de El agua mansa se conserva en la biblioteca del Institut del Teatre de Barcelona, colección Sedó, Vit. A, Est. 5 (puede verse la edición de Arellano y García Ruiz); el de El mágico prodigioso, del que se han perdido los folios finales, se conserva en la BNE con la signatura Vitr/7/1.

${ }^{5}$ En lo que respecta al manuscrito de Basta callar (el Res. 91 de la BNE), las intervenciones autógrafas afectan a "portada (menos nombres de actores introducidos a la izquierda); f. 23v, últimas 10 líneas; f. 26v (final de la I jornada); lista de "personas nuebas", f. 53v; pequeñas enmiendas en las tres jornadas", de acuerdo con la entrada correspondiente al manuscrito en el portal de Manos teatrales: <https://www.manos.net/manuscripts/bne/res-91-basta-callar> [consulta: 1/ 7/2015]; las partes autógrafas del manuscrito de Cada uno para sí (BNE Ms. 16.887) comprenden los fols. 78r-81v y 84r-86r (Calderón de la Barca, 1982: 4).

${ }^{6}$ Puede verse Cruickshank (1973: 6-10), así como su edición de la Tercera parte (Calderón de la Barca, 2007); Suárez y Manjarrez (2008); e Iglesias Feijoo y Ulla Lorenzo (2011: 31-37).

${ }^{7}$ Sobre esta obra han escrito Ashcom (1973) en un artículo poco valioso, Montarnal y Vitse (1968) y Manjarrez (2007).
} 
caso de La dama duende ${ }^{8}$. En algunas comedias la duda se cierne sobre el propio texto autorizado, como sucede en Judas Macabeo, pues algunos de los cambios que están presentes en la versión presumiblemente avalada por el propio autor chocan con lo esperable de una concienzuda revisión autorial y quizá estuviesen ya presentes en el texto que llegó a las manos de Calderón mientras preparaba la Segunda parte ${ }^{9}$. Sí podemos saber, además, o al menos deducir, que en varios de los ejemplos señalados (El astrólogo fingido, La vida es sueño, Judas Macabeo), la segunda versión se construyó a partir de un texto de la primera que no coincide, en un grado difícil de establecer, con el que ha llegado hasta nosotros, lo que impide estudiar con total exactitud el proceso de reescritura (Calderón de la Barca, 2008: 96-105; 2011: 75-84 y 2012: 58-65).

Y también cabe señalar, como otro elemento problemático más, que, aunque normalmente el texto autorizado suele corresponderse con la versión reescrita, de tal manera que la primera versión ha llegado a nosotros a través de cauces manuscritos o de ediciones no vigiladas por el dramaturgo, no siempre es así, como sucede con El mágico prodigioso y El agua mansa. De estas dos comedias se conservan sendos autógrafos que se corresponden con las respectivas primeras versiones de ambas, pues se ha considerado que los textos contenidos en ediciones antiguas no autorizadas - la Parte veinte de comedias varias nunca impresas (Madrid, 1663), en el caso de El mágico prodigioso; la Octava parte de comedias nuevas escogidas de los mejores ingenios de España (Madrid, 1657), en el de Guárdate del agua mansa- se corresponden con sendas revisiones acometidas por el propio Calderón, en un caso para adaptar la comedia - escrita en un principio para ser representada con carros, al modo de los autos sacramentales, durante las fiestas del Corpus de Yepes en 1637- al corral, y en el otro para adecuarla a una representación llevada a cabo para festejar la llegada a España de Mariana de Austria en noviembre de 1649. Pero estos dos casos difieren también en la consideración de la versión reescrita, ya que, mientras en el de El mágico prodigioso la versión canónica ha tendido a ser la segunda, a pesar de no haberse conservado autógrafa (Calderón de la Barca, 1985 y 2009), en el de El agua mansa, desde la edición del autógrafo se ha relegado la segunda versión por considerarse una adaptación de la primera realizada por motivos circunstanciales (Calderón de la Barca, 1989).

Pero, si los casos de reescritura en los que al menos uno de los testimonios está autorizado ofrecen ya suficientes problemas, más se complica aún la situa-

8 Tal es la postura de Antonucci (Antonucci y Vitse, 1998: 49-64), compartida por Pedraza (2000: 212-213). Frente a ellos considera Vitse ambas versiones plenamente calderonianas (Antonucci y Vitse, 1998: 64-71).

${ }^{9}$ Pueden verse las dudas que exponía en mi edición de la comedia (Calderón de la Barca, 2012: 111-115, y también Rodríguez-Gallego, 2010: 179-180), así como la valiosa reseña de Antonucci (2013). 
ción en el tercer grupo señalado al principio, aquel en el que ninguna de las dos versiones se conserva en un texto autorizado, categoría en la que hemos de incluir hasta el momento La señora y la criada / El acaso y el error, La banda y la flor / Hacer del amor agravio y la comedia que nos ocupa, Las manos blancas no ofenden. En estos casos se acentúan los problemas relativos a la cronología de las versiones y a la propia categoría que queramos darles, según entendamos que ambas son calderonianas, solo una de ellas, o incluso que ninguna se ajusta por completo a texto alguno salido de la pluma de don Pedro.

En relación con este último aspecto cobra especial protagonismo la figura del que se proclamaba a sí mismo mayor amigo de Calderón: Juan de Vera Tassis y Villarroel, quien ha hecho correr ríos de tinta entre los calderonistas ${ }^{10}$. Si en los otros dos grupos señalados las dudas ante sus ediciones se reducían, pues contábamos al menos con un texto autorizado que servía de piedra de toque, en este último grupo puede darse el caso de que el mejor de los textos conservados, al menos en apariencia, sea el editado por Vera, lo que ya nos sitúa ante la evidencia de que tenemos que vérnoslas con un texto que no es de Calderón al cien por cien, pues es notorio el gusto de Vera por el intervencionismo. Al desconocerse además en estos casos en qué textos se basaba Vera, no podemos saber en qué medida este se mostraba respetuoso con un buen texto base, o bien manipulaba a su gusto un texto en malas condiciones. Algunos rasgos peculiares de la manera de editar de Vera se conocen ya, lo que puede ayudarnos a reconstruir la lectura supuestamente original de Calderón. Pero esta manera de operar es arriesgada, cuando aún carecemos de un buen estudio de la lengua calderoniana basada exclusivamente en sus autógrafos, o incluso de una base de datos que recoja los textos de los autógrafos calderonianos, herramienta que podría resultar muy útil en estas situaciones.

En el caso de El acaso y el error y La señora y la criada se ha discutido mucho el orden de las dos versiones. Covadonga Romero, su más reciente editora, no expresa una opinión tajante:

Con el estado actual de los textos no hay modo de saber cuál fue el primero. Si aceptamos que La señora se escribió antes, entonces El acaso sería una reelaboración con el agregado de nuevos versos. Pero pudo ser perfectamente al revés, que La señora reelabore El acaso, optando ahora Calderón por suprimir versos (Romero, 2007: 92) ${ }^{11}$.

Cruickshank (2009: 172, 312-313), por su parte, considera más plausible que El acaso y el error sea reelaboración de La señora y la criada.

${ }^{10}$ Cruickshank (1983) traza una aproximación a su figura y su trabajo, y Rodríguez-Gallego (2013) un estado de la cuestión sobre su labor editorial.

${ }^{11}$ Covadonga Romero ha publicado una edición de ambas comedias en la editorial Juan de la Cuesta (Calderón de la Barca, 2015c) que todavía no he podido consultar. 
Los problemas de trabajar con textos no autorizados se aprecian también en lo que respecta a La banda y la flor. De la comedia existen dos versiones: una larga, publicada de manera anónima en la Parte treinta de la colección de Escogidas (Madrid, 1668) con el título Hacer del amor agravio, y otra corta, recogida en la facticia Parte sexta de Escogidas ("1654") y editada por Vera Tassis en la Octava parte de Calderón (1684). A primera vista, la fiabilidad del texto recogido en la Parte treinta de Escogidas es menor, ya que se publicó como anónimo y con un título alejado del que el propio Calderón consignó en la lista de Carlos II y en la de Veragua. Sin embargo, cuenta con 305 versos no presentes en La banda y la flor, versos no imprescindibles en el desarrollo de la trama y que parecen de Calderón, pues varios de ellos se documentan en otras comedias del poeta, de tal modo que lo más plausible es que algún autor de comedias suprimiese estos versos para acortar la comedia, ya que la operación contraria — añadir versos que no aportan nada sustancial a la acción — resulta menos probable. Así, la versión publicada bajo el título Hacer del amor agravio, a pesar de sus abundantes errores, parece haber sido la escrita por Calderón, o se aproxima más a ella, mientras que el texto incluido en la Sexta parte de Escogidas y la Octava de Calderón se correspondería más bien con un manuscrito de compañía en el que se habrían suprimido varios versos de la comedia ${ }^{12}$. Se trataría de un proceso similar al que pudo haber acontecido con la comedia Basta callar, de la que Vera editó una versión corta en la que faltan versos atajados en el manuscrito Res.91, de lo que puede deducirse que se basó en un texto que ya no hubiese contenido estos versos, que es lo que sucede, por ejemplo, en el manuscrito 17069 de la BNE.

Un problema similar parece plantear, al menos de acuerdo con lo que defiende en su más reciente edición Martínez Blasco (Calderón de la Barca, 1995b), Las manos blancas no ofenden, comedia escrita en torno a 1640 (Calderón de la Barca, 1995b: 71-77; Cruickshank, 2009: 256). Según sostiene su editor, de esta comedia disponemos "de dos textos o, mejor aún, dos versiones de un mismo texto" (Calderón de la Barca, 1995b: 125). Una de ellas, la más larga, es la editada por Vera Tassis en la Octava parte de Calderón (Madrid, 1684), en tanto que la otra se conserva en la Parte nona de la colección de Escogidas (Madrid, 1657), publicada casi treinta años antes ${ }^{13}$. Martínez Blasco parece conside-

${ }^{12}$ En su reciente edición de la comedia (Calderón de la Barca, 2015a), Jéssica Castro se inclina, sin embargo, por editar el texto más breve de La banda y la flor.

${ }^{13}$ En la Parte nona se recoge también El escondido y la tapada, que Vera Tassis publicó en la Parte séptima de Calderón (1683). Larrañaga Donézar (1989) toma como base de su edición de la comedia el texto de la Parte nona, a pesar de que "le faltan diez versos, presenta incompletos dieciocho y tiene irregularidades métricas en veintisiete" (1989: 69). También Escudero (2009: 135-137) destaca las numerosas malas lecturas de la Parte nona corregidas por Vera, pero se inclina por creer que las correcciones de Vera son "legítimas" (2009: 141), es decir, que provienen de la consulta de algún otro texto, antes que adjudicarlas al arbitrio de Vera. Para sustentar esta opinión se sirve en parte del caso de Las manos blancas no ofenden. 
rar ambas autoriales, pues "[n]o creemos que Vera Tassis fuese capaz de añadir tantos versos y variantes a su edición de 1684" (Calderón de la Barca, 1995b: 125), aunque al mismo tiempo desacredita las dos versiones, ya que, de acuerdo con él, el de Escogidas "es un texto poco seguro, con muchas erratas, que por algunos errores parece proceder de un manuscrito, pues hay lecturas típicas de una mala lectura [sic]", y del de Vera entiende que "procede igualmente de otro manuscrito, donde, también se ofrecen lecturas confusas, nacidas de una lectura difícil" (Calderón de la Barca, 1995b: 125).

Lamentablemente, el editor ni justifica ni argumenta estas aseveraciones. Tampoco incluye en su edición un estudio textual, ni da un solo ejemplo de diferencias entre ambas versiones, por lo que, para poder estudiar estas, el lector interesado deberá analizar las variantes consignadas de manera no muy completa en nota al pie o bien acudir a los textos originales, accesibles hoy en la Biblioteca Digital Hispánica.

Una primera versión de este trabajo surgió, así, de la atenta lectura de la edición de Martínez Blasco, por lo que se centró en un principio en la relación entre los dos impresos. Del examen de las diferencias entre ambos se observaba que uno, la edición de Vera Tassis, estaba completo y apenas tenía errores, mientras que al otro, el de Escogidas, le faltaban decenas de versos y contaba con innumerables errores: más que ante dos versiones de la comedia parecía que estábamos ante una sola, representada por el texto de Vera, mutilado y estragado en la edición de Escogidas.

Sin embargo, de la comedia existen también dos manuscritos (BNE Mss. 16467 y 15390), sin fecha ni censuras, a los que Martínez Blasco (Calderón de la Barca, 1995b: 132-133) dedica poco más de una página. De acuerdo con él, el 16467 es "apenas legible" y "no tiene continuidad", mientras que el 15390 sigue "la edición de Vera Tassis", a lo que añade una frase bastante confusa: "Naturalmente este manuscrito recoge los textos de 1657 ampliados en la edición de 1684, aunque en algún caso mejora el texto primitivo" (Calderón de la Barca, 1995b: 132). De todos modos, el editor solo recoge variantes del Ms. 15390 durante los 107 primeros versos de la comedia, lo que impide que el lector se haga una idea cabal del contenido de ambos.

La digitalización de los dos manuscritos y su puesta a disposición de los lectores en la Biblioteca Digital Hispánica nos permite comprobar que su marginación por parte de Martínez Blasco es infundada, ya que ofrecen variantes de interés que los aproximan más a la versión de Escogidas, aunque sin la mayor parte de los errores de esta, que al de Vera Tassis. De hecho, y como tendremos ocasión de comprobar, una edición crítica de la comedia deberá atender a los cuatro testimonios, pues de su cotejo se podrá evidenciar que el más defectuoso y menos completo de ellos es la edición de Escogidas, al tiempo que la cuestión de la posible existencia de dos versiones de la comedia pierde importancia. Así, atender solo a 
las dos ediciones manejadas por Martínez Blasco nos da tan solo una imagen muy pálida de los problemas textuales de Las manos blancas no ofenden, que resultan de gran complejidad cuando se tienen en cuenta también los manuscritos ${ }^{14}$.

Como adelantábamos, el cotejo nos muestra que de la comedia se conserva una versión larga, representada por la edición de Vera Tassis, y una corta, contenida en los otros tres testimonios. Si atendemos en primer lugar a diferencias numéricas, observamos que en el texto de Vera Tassis existen 145 versos no presentes en los otros tres testimonios, sin que la ausencia de estos versos deje rastro $^{15}$. A estos cabría añadir otros tres y medio de los que se tratará más adelante, pues su ausencia en $E, M 1$ y $M 2^{16}$ sí afecta a la métrica, por lo que propiamente estaríamos ante errores comunes de estos tres testimonios.

De esos 145 versos solo presentes en VT, hasta 141 se encuentran en la primera jornada, mientras que los otros cuatro están en la tercera. De ellos, una importante mayoría son grupos de dos o cuatro versos incluidos en romances y que en muchas ocasiones funcionan a manera de incisos, por lo que bien pudieron haberse perdido en la transmisión, quizá por haber sido atajados en algún manuscrito, pues en su gran mayoría desaparecen sin que métrica o sentido se vean afectados, como en el siguiente ejemplo:

$V T$

Vila, Teodoro, y vi en ella

la beldad más soberana

que pudo en su fantasía

- lámina haciendo del aura,

del pensamiento colores-

jamás dibujar la varia

imaginación

(p. 58b; vv. 941-947) $)^{17}$

\section{E / $M 1 / M 2$}

Vila, Teodoro, y vi en ella

la beldad más soberana

que pudo en la fantasía

jamás dibujar la vaga

imaginación

(p. $11 \mathrm{~b}$; fol. $18 \mathrm{r}$; fols. $18 \mathrm{v}-19 \mathrm{r}$ )

${ }^{14}$ A la edición crítica de la comedia dedica en la actualidad su tesis de doctorado Verónica Casais Vila en la Universidad de Santiago de Compostela. En ella tendrá en cuenta, de manera exhaustiva, todos los testimonios de la comedia, lo que permitirá mejorar en gran medida el texto editado por Martínez Blasco. Sobre la primera jornada de la comedia puede verse ya Casais Vila (2014), trabajo ceñido solo a la tradición impresa.

15 Según Martínez Blasco, que no tiene en cuenta los manuscritos, el texto de Escogidas "tiene más de doscientos versos menos que la edición [de Vera Tassis]" (Calderón de la Barca, 1995b: 125), aunque de mi cómputo resulta una cantidad inferior. Quizá Martínez Blasco haya tenido también en cuenta aquellos versos en los que la lección de Vera difiere por completo de la de Escogidas, aunque en todo caso no da ejemplos ni aventura ninguna teoría sobre estos versos de diferencia entre los dos testimonios.

16 Para referirme a los testimonios de manera abreviada, utilizaré la sigla $E$ para la Parte nona de Escogidas, VT para la Octava parte de Calderón editada por Vera Tassis, M1 para el ms. 16467, y $M 2$ para el 15390.

17 La numeración de versos se corresponde, para comodidad del lector, con la edición de Martínez Blasco. Otros ejemplos de este tipo de omisiones pueden verse en los versos 195-196, $198-199,242-243,475-478,527-528,847-850,871-874,1639-1640$ у 1653-1654. 
En dos casos los versos de VT que se pierden en la otra rama son sustituidos por uno que evita que la laguna afecte a la métrica o el sentido. Así sucede aquí:

$V T$

¿qué he de hacer yo en el concurso de tantos como la aman, si apenas los nombres sé de lo que es tela o es valla? $Y$, si la verdad confieso, solo el pensarlo me espanta, que no en vano a la costumbre todos en el mundo llaman segunda naturaleza. (p. 60b; vv. 1109-1117)
E / M1 / M2

¿qué he de hacer yo entre el concurso de tantos como la aman, si apenas los nombres sé de lo que es tela ni valla, fuste, brida, ristre o cuja? ${ }^{18}$ (p. 13a; fol. 21r; fol. 22r) ${ }^{19}$

La misma tónica se aprecia en grupos de versos más grandes: de seis (vv. 519-524), de ocho (vv. 437-444) y, en especial, tres cortes de mayor envergadura: uno de veinte (vv. 1356-1375), otro de veintidós (vv. 1041-1062) y otro de cuarenta y dos (vv. 263-304), el más importante de todos. Pero también se trata de cortes limpios, o bien existen las modificaciones necesarias que hacen que no queden afectados métrica ni sentido, ya que los versos solo presentes en $V T$ no contienen informaciones fundamentales para el desarrollo de la trama ${ }^{20}$.

Así, dado que las omisiones de los versos solo presentes en $V T$ no se suelen apreciar en $E, M 1$ y $M 2$, parece que los de $V T$, antes que añadidos en este testimonio, son versos originales perdidos en la otra rama (a pesar de ser $E$ un testimonio anterior a $V T$ ) quizá por la acción de un autor de comedias que quiso recortar la larguísima primera jornada, la más extensa de la comedia con nada menos que 1678 versos en la versión de Vera, de acuerdo con el cómputo de la edición de Martínez Blasco. De este modo, $V T$, al menos en lo que respecta a estos pasajes, se acercaría más a una primera versión.

Al tiempo, también se da, aunque en mucho menor grado, la situación contraria: que $E, M 1$ y $M 2$ tengan versos no presentes en $V T$. En el siguiente pasa-

${ }^{18} E$ presenta en este verso el error caja por cuja. Siempre que en los textos citados haya variantes sin importancia (normalmente errores de $E$ ) en los versos que sirven para contextualizar la variante fundamental, no se indicarán.

${ }^{19}$ Lo mismo sucede con los versos $1668-1670$ de $V T$, sustituidos por uno distinto en la rama E M1 M2.

${ }^{20}$ Sin embargo, hay también algún caso en el que la ausencia de versos sí hace que el texto de $E, M 1$ y $M 2$ se resienta, por lo que estaríamos más bien ante un error, como sucede en los versos 757-760 y 771-772. En ellos César repite lo que cantan dos damas, de acuerdo con lo que sucede en toda esa escena, pero son omitidos por probable error en $E, M 1$ y $M 2$, tal vez por haber sido considerados por algún copista, que no entendió el sentido de la escena, una repetición errónea. 
je, los versos de $E, M 1$ y $M 2$ respetan el esquema del romance en el que se insertan, pero tienen un sentido no muy claro, y rompen la transición entre "templada la saña esté" y "Así su saña templara". De hecho, en M2 fueron atajados y se escribió no al margen:

$V T$ haced que la góndola en la arena varada aguarde hasta que de la cólera del Po templada la saña esté.

CARLOS Así templara su saña...

SERAFINA Basta; no me digáis quién. (p. 63b; vv. 1324-1330)
$E / M 1 / M 2$

haced

que la góndola en la arena varada aguarde hasta que de la cólera del Po templada la saña esté, y vuelva a cobrar su copa aquel rogado laure $^{21}$ coronando ${ }^{22}$ de esperanzas al piloto que le ve.

CARlos Así su saña templara...

SERAFINA Basta; no me digáis quién. (p. $15 \mathrm{~b}$; fol. $25 \mathrm{r}$; fol. $27 \mathrm{rv}$ )

En el ejemplo siguiente, situado justo después de una larga omisión en $E$, $M 1$ y $M 2$ de versos de $V T$, un chiste puesto en boca de Patacón solo está presente en aquellos:

\section{$V T$}

LAURA $\quad[\ldots]$ Atrás el paso volved que está la princesa aquí. (p. 64a; vv. 1376-1377)

\section{LAURA \\ PATACÓN}

FEDERICO

\section{E / M1 / M2}

Atrás, hidalgos, volved, que está la princesa aquí. Por eso está aquí también el princeso.

Calla, loco $^{23}$. (p. 16a; fol. 26r; fol. 28r)

Era habitual que los versos puestos en boca de los graciosos fuesen víctimas de las supresiones en las revisiones de textos, como mostró Cruickshank para En la vida todo es verdad y todo mentira (Calderón de la Barca, 1971: xiixvi), por ejemplo, aunque también podía darse el caso de que un autor de comedias añadiera para el donaire gracias de su propia cosecha, como mostró Ruano de la Haza que hizo Escamilla en el ya mencionado manuscrito BNE 16.887 de Cada uno para sí (Calderón de la Barca, 1982: 59-60). Sin embargo, la réplica "Calla, loco", o alguna similar, es muy habitual en comedias de Cal-

\footnotetext{
${ }^{21}$ rogado $M 2$ : rozado $E$. $M 1$ parecía leer también rogado, pero una segunda mano corrigió en sagrado.

22 coronando $M 1$ : coronado $E M 2$

${ }^{23}$ loco $M 1 M 2$ : un poco $E$.
} 
derón ante chistes de los graciosos, por lo que probablemente el pasaje sea original, se conservó en $E, M 1$ y $M 2$ y no llegó a $V T$ por haber sido suprimido en algún testimonio anterior o en aquel en el que se basaba Vera, si es que no fue este el que lo eliminó por parecerle impropio ${ }^{24}$.

Estos versos presentes solo en una u otra rama constituyen la diferencia más llamativa entre ellas, pero la existencia de ambas viene confirmada por otros aspectos, como una serie de errores comunes de $E, M 1$ y $M 2$ no presentes en VT:

$V T$

[ENR.] tan gran dicha. SERAF. A ti los brazos (p. 76a; v. 2276)

Pues a ti te busca. ¿Qué te suspende ni ofusca? (p. 79a; vv. 2507-2508)

SERAFINA Un guante se me ha caído. PATACÓN. ;Mas que anda ruido sobre el guante! CARLOS Yo...

FEDERICO Yo he de levantarle.

(p. 91b; vv. 3446-3449)
E / M1 / M2

[ENR.] tan gran dicha. SERAF. Los brazos (p. $27 \mathrm{a}$; fol. $45 \mathrm{v}$; fol. $52 \mathrm{v}$ )

Pues a ti te busca.

[...]

(p. 30a; fol. $50 \mathrm{v}$; fol. $58 \mathrm{v}$ )

SERAFINA Un guante se me ha caído. FEDERICO Yo he de levantarle. (p. 41b; fol. 69r; fol. 79v)

Existen también lecturas equipolentes que asientan la existencia de estas dos ramas:

$V T$

pero cuando no le sale tan a su gusto el objeto (p. 52a; vv. 427-428)
E / M1 / M2

pero cuando no le sale tan a su gusto el bosquejo (p. 5 b; fol. $8 \mathrm{v}$; fol. $9 \mathrm{r}$ )

${ }^{24}$ Complejo es el caso de los versos 1669-1670 de VT, sí presentes en E M1 M2 solo que en otro lugar, a continuación del verso 1570. En otros pasajes, son solo uno o dos testimonios los que tienen versos no incluidos en los demás. Tras el verso 122 existen dos solo presentes en $E$ y M1 que pueden considerarse erróneos, ya que rompen el esquema de redondillas (de hecho, en $M 1$ una segunda mano intentó arreglar el pasaje aproximando su texto al de $V T$ y $M 2$ ). Tras el 1510 es solo $E$ el que añade dos versos, que, aunque encajan métricamente, rompen el paralelismo presente en VT M1 M2 entre las intervenciones de Federico y Carlos, que acaban de salvar a Lisarda y César, respectivamente. M2 añade dos versos tras el 4019 que están atajados en el manuscrito, aunque se escribió un Sí al margen. Tras el 4101 añade otros dos, pero en este caso en el margen, lo que los hace sospechosos. En otros tres lugares (tras los versos 1287, 1581 y 3446 b) hay versos en $M 2$ no presentes en los otros testimonios, aunque sí fueron incluidos en $M 1$ por una segunda mano. Resulta difícil juzgar la autenticidad de estos versos, que no puedo analizar aquí en detalle por falta de espacio, aunque en caso de aparecer en un solo testimonio prima la cautela. Sobre otros versos solo conservados en $M 1$ (ya por su primera mano) y $M 2$ se tratará más adelante. 
de hombre tan ruin y grosero

(p. 55a; v. 662) de hombre tan vil y grosero

(p. 8a; fol. 13r; fol. 13r $)^{25}$

Las diferencias alcanzan a veces a versos enteros:

$V T$

Tápate y vente a esconder

y tú puedes responder,

pues que yo no sé quién sea

(p. 47b; vv. 74-76)
E / M1 / M2

Tápate y vete a esconder y di tú a ese bachiller, pues que yo no sé quién sea (p. $2 \mathrm{a}$; fol. $2 \mathrm{v}$; fol. $2 \mathrm{v})^{26}$

Y en ocasiones a pasajes algo más largos:

$V T$

mas bien sé, si en las acciones de un diestro pintor lo advierto, pues, cuando labra, estudioso, alguna imagen al lienzo, arrima el tiento y descansa luego la mano en el tiento (pp. 51b-52a; vv. 413-418)
E / M1 / M2

pero sí sé si a un pintor en sus acciones atiendo, pues cuando para labrar ${ }^{27}$ alguna imagen al lienzo, arrima el tiento y descansa luego la mano en el tiento (p. 5 b; fol. $8 \mathrm{v} ;$ fol. $8 \mathrm{v})^{28}$

Cabe preguntarse si se trata de variantes de autor, o bien si se generaron por problemas de transmisión, para rellenar lagunas o corregir errores, aunque hay que mencionar que, en todo caso, estas lecturas equipolentes no son muy abundantes, teniendo en cuenta que estamos ante una comedia que alcanza los 4353 versos en la versión de $V T$.

Así, a primera vista, el panorama textual de Las manos blancas podría parecer sencillo, ya que el editor habría de elegir el texto de $V T$, más completo, frente al de la otra rama, y acaso corregirlo en caso de error evidente o de variante propia del ilustre editor de Calderón. Sin embargo, las cosas no son tan simples, pues junto a estas importantes variantes que agrupan a $E, M 1$ y $M 2$ frente a $V T$, encontramos otras que combinan los cuatro testimonios en todas las soluciones posibles. Así, son frecuentes los pasajes en que E y $M 1$ comparten lectura frente a $V T$ y $M 2$, como sucede en estos errores comunes de aquellos:

\footnotetext{
${ }^{25}$ Pueden verse otros ejemplos en los versos 60, 140, 319, 395, 479, 926, 934, 1581 o 3908.

${ }^{26}$ Otro ejemplo en el v. 2855, en el que parece mejor lectura la de $E M 1 M 2$.

${ }^{27}$ labrar $E M 1$ : formar $M 2$

${ }^{28}$ Otro ejemplo en los versos 558-560.
} 
$V T$ / M2

Toda su fábrica hermosa, ruina del voraz incendio, pirámide era de humo

(p. 52b; fol. 10r; vv. 493-495)

A ti solo, por no hallar mujer en el mundo sabia [...], me dio por maestro de quien he aprendido lo que llaman buenas letras (p. 58a; fols. 17v-18r; vv. 893-899)
E / M1

Toda su fábrica hermosa, reina $^{29}$ del voraz incendio, pirámide era de humo (p. 6b; fol. 9v)

$A s i^{30}$ solo, por no hallar mujer en el mundo sabia [...], medio, por medio ${ }^{31}$ de quien he aprendido lo que llaman buenas letras (p. 11a; fol. 17v)

Podemos añadir el siguiente lugar, en el que $E$ y $M 1$ comparten una laguna que es detectada y solventada por una segunda mano en $M 1$, que recupera el texto de $V T$ y $M 2$ :

\section{$V T / M 2$}

CArlos Aunque esa es sofistería, ¿quién fue quien se la dio?

FEDERICO Quien

(bien entrara aqui ${ }^{32}$ la joya; ¡mal haya Lisarda, amén!), cuando otros de reposar, trataba de padecer (p. 65a; fol. 30r; vv. 1447-1452)

\section{E / M1}

CARlos Aunque esa es sofistería, ¿quién fue quien se la dio?

FEDERICO cuando otro de reposar, trataba de padecer (p. 17a; fol. 27v)

$V T$ y $M 2$ coinciden también frente a $E$ y $M 1$ en la que puede considerarse la variante más interesante de la comedia que no se refiere a lagunas y en la que sí se puede hablar claramente de reescritura. Se trata de una intervención de Fabio de 19 versos en $V T$ y $M 2$ y de 15 en $E$ y $M 1$ que difieren por completo. Fabio es un amigo de Federico, pero está enamorado de Lisarda, quien también es amada por Federico, a quien Lisarda corresponde. Los versos en cuestión son pronunciados por Fabio mientras busca a Federico, al enterarse de que este tiene intención de marcharse de Milán y abandonar a Lisarda:

\footnotetext{
${ }^{29}$ En $M 1$ una segunda mano corrige en ruina.

${ }^{30}$ De nuevo una segunda mano en $M 1$ corrige en $a t i$, aunque la primera lectura parece haber sido así.

31 Aquí $M 1$ aún tiene una lectura más absurda: "me dio que me dio por medio de quien".

32 aquí $V T$ : ahora $M 2$

${ }^{33}$ Los versos de $V T$ y $M 2$ omitidos en $E$ y $M 1$ fueron añadidos en $M 1$, con ligeras variantes, por una segunda mano: "Bien entraba ahora la joya; / ¡mal haya Lisarda, amén!”.
} 
$V T / M 2$

FABIO Loco pensamiento mío, no te quejarás de mí, porque no fíe de ti el mal que de mí no fío, pues, cuando pedir pudiera albricias de que hoy se va quien tantos celos me da con la más hermosa fiera destos montes y estos mares, no permite mi esperanza que tome tan vil venganza a costa de los pesares de la ausencia de un amigo a quien ofendió el deseo. $\mathrm{Y}$, pues a callar me veo obligado, ni aun conmigo lo he de hablar. Séllese el labio y quien alivio no espera, sufra, calle, gima y muera. (pp. 47b-48a; fol. 3r; vv. 89-107)

\section{E / M1}

FABIO Bien pensará quien me viere afectar el sentimiento desta ausencia, que es a intento de que a mi amistad $^{34}$ prefiere a la mayor, siendo así que no es sino esperanza ${ }^{35}$ de que he de tomar $^{36}$ venganza de Lisarda, viendo aquí que, si tirana me deja, es a lo menos por quien a ella ${ }^{37}$ la deja también. Confieso que es vil la queja, pero queja que es agravio de unos celos, ¿cuándo es más noble ni más cortés? (p. 2ab; fol. $3 \mathrm{v}$ )

Puede notarse que en el texto de $V T$ y $M 2$ el personaje se ennoblece, ya que, mientras en $E$ y $M 1$ muestra su contento por que Federico se marche, lo que a él le servirá de venganza con respecto a Lisarda, en $V T M 2$ dice que, aunque podría alegrarse por la ausencia de Federico, no lo hará por respeto hacia la amistad que sentía por él, de tal manera que el texto de VT M2 encajaría mejor con la aristocratización de los personajes que Marc Vitse ha señalado con respecto a los protagonistas del teatro de Calderón. Pero lo que es difícil de asentar es si VT M2 constituye una versión reescrita del texto de $E M 1$, acometida quizá por Calderón para dar una nueva perspectiva al personaje en ese lugar concreto, o bien si el texto de $E M 1$ es una simplificación del de VT M2, con el objetivo de que no sea tan compleja la respuesta del personaje y que el espectador lo encaje con más facilidad en la categoría de amante celoso, y en cierto modo, de malo, rival de Federico.

Además, la variante de este pasaje parece estar relacionada con esta otra intervención de Fabio, que se encuentra en un diálogo posterior entre este y Lisarda, todavía en la primera jornada:

\footnotetext{
${ }^{34}$ a mi amistad: en $M 1$ una segunda mano tachó la $a$, lo que parece tener más sentido.

35 esperanza: en $M 1$ una segunda mano corrige el verso y añade una en la interlínea.

${ }^{36}$ he de tomar $M 1$ : ha de tener $E$

${ }^{37}$ a ella $M 1$ : ella $E$
} 
$V T / M 2$

FABIO Bien pudiera yo vengarme, Lisarda, de tus desprecios ${ }^{38}$ con tus desprecios, mas es noble mi amor, y no quiero que tus sentimientos sean despique a mis sentimientos, ${ }^{39}$ y, así, llóralos ${ }^{40} \sin m i ́$ porque, al verte llorar, temo que a alguna ruindad me obligue o mis celos o tus celos. ${ }^{41}$ (pp. 54b-55a; fol. 13r; vv. 647-656)
E / M1

FABIO Bien pudiera yo vengarme, Lisarda, de tu desprecio ${ }^{42}$ en tus desprecios, mas no lo he de intentar, porque temo que [a] alguna ruindad me obliguen o tus celos o mis celos. ${ }^{43}$ (p. $8 \mathrm{a}$; fol. $12 \mathrm{v}-13 \mathrm{r}$ )

Como se puede observar, en los versos solo presentes en $V T$ y $M 2$ de nuevo resulta Fabio ennoblecido con respecto al texto de $E M 1$, aunque sigue presente la duda de si es en este en el que se quiere simplificar el personaje, o si es en el de VT M2 en donde se interviene para ennoblecerlo. A primera vista, quizá lo más sencillo sea entender que se trata de variantes de autor debidas a Calderón, pues sería complicado entender las razones que habrían podido llevar a un autor de comedias a realizar esos cambios. Contamos, sin embargo, con al menos una situación paralela en La desdicha de la voz, comedia de la que se ha conservado el manuscrito autógrafo (BNE Res. 108). En este Calderón realizó abundantes cambios, suprimió versos y reescribió incluso escenas enteras. La versión de la comedia con estas modificaciones, a las que se añadieron diferentes errores y lagunas, fue la que pasó a la tradición impresa: Parte 43 de la colección de Diferentes autores (Zaragoza, 1650), Séptima parte de Calderón (ed. Vera Tassis, Madrid, 1683) y varias sueltas.

Un caso que se sale de las pautas regulares de transmisión de la comedia lo encontramos en los versos 1835-1904, siete décimas puestas en boca de don Juan, quien monologa sobre su situación, también de amante celoso. En la tradición impresa, estos setenta versos fueron sustituidos por cuarenta, también en forma de décimas, completamente diferentes y que simplifican los setenta originales. En el autógrafo de Calderón las siete décimas se encuentran en el recto y el verso del fol. 31, y carecen de atajos o de correcciones de envergadura, fren-

\footnotetext{
38 tus $V T:$ mis $M 2$

${ }^{39}$ despique a mis sentimientos $V T$ : despiques a mis celos $M 2$. En $M 2$ los versos no están bien repartidos, lo que quizá explique esta variante, ya que quedaría un verso: sean despiques $a$ mis celos.

40 llóralos $V T$ : llorarlos $M 2$

${ }^{41}$ o mis celos o tus celos $V T$ : o tus celos o mis celos M2 (que coincide aquí con E y M1).

${ }^{42}$ En $M 1$ la segunda mano corrige el verso en: "tirana, de mis desprecios", aunque la primera lectura parece coincidir con la de $E$.

${ }^{43}$ o tus celos o mis celos $M 1$ : a tus celos los mis celos $E$
} 
te a lo que sucede en otros lugares del manuscrito. En su edición crítica de la comedia, Mason considera la versión impresa de este pasaje "much inferior", por lo que la rechaza y edita sin dudarlo el texto del autógrafo, y añade:

It is tempting to conjecture that Calderón's original must have been rejected by the actors, with or without his consent, in the interests of brevity; certainly the autograph bears no indication that Calderón was any way dissatisfied with the speech as originally composed (Calderón de la Barca, 2003: 10).

Quizá cabría pensar que, en lo que respecta a Las manos blancas, sucedió algo similar. Tal vez en una compañía se quisieron reescribir y acortar ligeramente los 19 versos puestos en boca de Fabio, además del pasaje posterior; o bien se tacharon por las razones que fuesen y después se quiso rellenar la laguna. Con los datos de que disponemos, todo son conjeturas, aunque sí hay que subrayar que destaca la reescritura de este pasaje en un panorama textual en el que las diferencias provienen normalmente de lagunas y omisiones de la rama E M1 M2.

Esta importante variante también parece dar a entender que $M 2$ podría ser visto como una suerte de estadio intermedio entre $V T$, por un lado, y $E M 1$, por otro. VT sería el texto más completo y (cabe suponer) más cercano al escrito por Calderón; en un primer momento, este texto habría sido recortado, particularmente en la primera jornada, estadio que representaría $M 2$, y sobre este texto más breve se habrían introducido las variaciones que afectan a los parlamentos de Fabio que se acaban de destacar, estadio representado por $E$ y $M 1$. Tal suposición parece confirmarla el hecho de que, en lo que respecta al segundo de los pasajes de Fabio comentados (vv. 647-656), en M2 encontramos simultáneamente las dos versiones. En efecto, la primera mano copió el texto tal cual se encuentra en $V T$, con muy leves variantes, pero los versos 650-654 fueron atajados, se escribió "no" en el margen izquierdo, y en el derecho se añadió un verso para sustituirlos, "lo he de intentar, porque temo". Para que el nuevo verso encajase, en el 649 se sobreescribió no encima de es, con lo que resultó la versión del pasaje que pasó a $E$ y $M 1$.

Sin embargo, otras variantes nos muestran que es imposible que $E$ y $M I$ desciendan de $M 2^{44}$, de tal modo que sería plausible que hubiese sido un revisor de $M 2$ el que, con algún otro testimonio a la vista, hubiese introducido ese atajo y esa corrección. Lo enrevesado de la transmisión de la comedia y las complejas intervenciones de segundas manos se aprecian también en estos otros pasajes en los que $E$ y $M 1$ presentan de nuevo lagunas detectables por métrica:

${ }^{44}$ Así sucede con la omisión en $M 2$ de los versos 747-750 y 4102-4103, sí presentes en $E$ y $M 1$, lo que imposibilita que estos testimonios desciendan de $M 2$. La transmisión tuvo que ser más compleja y probablemente hayan existido casos de contaminación. 
$V T$

Pues de verle

hay más que pensar que piensas, hay más que entender que entiendes. (p. 98b; vv. 3951-3953)

\section{E / MI}

Pues de verle

hay ${ }^{45}$ más que pensar que piensas.

[...] (p. 47b; fol. 78v)
M2

Pues advierte

que hay más que pensar que piensas, por mucho (jay de mí!) que pienses. (fol. 89r)

M1 (segunda mano)

Pues advierte

que hay más que pensar que piensas, por mucho (;ay de mí!) que pienses.

Frente al pasaje que vimos anteriormente, en el que $E$ y $M 1$ coincidían en una laguna frente a $V T$ y $M 2$, y el verso perdido era recuperado en $M 1$ por una segunda mano, en este también existe una laguna en $E$ y $M 1$, solo que el verso perdido difiere en $V T$ y $M 2$. Una segunda mano recupera el verso en $M 1$, y lo hace de acuerdo con M2. Así, debemos pensar, en primer lugar, que probablemente uno de los dos versos (el de $V T$ o el de $M 2$, si es que incluso no los dos) no es genuino, sino que fue inventado por alguien para paliar una laguna. Al tiempo, parece existir algún tipo de relación entre $M 1$ y $M 2$, ya que, o bien la segunda mano de $M 1$ dispuso de un texto similar a $M 2$, y de él tomó el verso, o bien fue en $M 2$ donde se seguía algún tipo de testimonio relacionado con $M 1$. Estos lazos entre ambos manuscritos se aprecian también en su coincidencia en "advierte / que", frente a la lectura "de verle / hay" de $E$ y $V T^{46}$.

Pero esta relación entre $M 1$ y $M 2$ no se da siempre:

$V T / M 2$

Mejor le hablaré sin ti, $\mathrm{y}$, así, permite que deje, antes que me halle contigo, este sitio y que me ausente. (p. $98 \mathrm{a}$; fol. $88 \mathrm{v}$; vv. $3920-$ 3923)

\section{$E / M 1$}

Mejor le hablaré sin ti, $\mathrm{y}$, así, permite que deje, antes que me halle contigo. [...] (p. 47b; fol. 78r)
M1 (segunda mano) Mejor le hablaré sin ti, $\mathrm{y}$, así, permite me ausente, antes que me halle contigo. Seraf. ¿Con quién mejor? ¡Oye, tente!

45 de verle / hay $E$ : advierte / que hay $M 1$

${ }^{46}$ En el verso 2779 de nuevo $E$ y $M 1$ omiten un verso requerido por métrica, además de coincidir en otros errores en los dos versos anteriores. La laguna no está presente ni en $V T$ ni en $M 2$, que de nuevo difieren en sus respectivos versos, aunque ambos tienen sentido y encajan bien en el pasaje. La segunda mano de $M 1$ corrige los errores presentes en el manuscrito y rellena la laguna de acuerdo con el texto presente en $M 2$. También en los versos 1472-1481 VT y M2 difieren en un lugar en el que $E$ y $M 1$ comparten un error, que una segunda mano en $M I$ corrige de acuerdo con $M 2$. Se trata de unos versos en los que dos personajes (Federico y Carlos en $V T$, Laura y Clori en M2) se distribuyen la narración de dos hechos simultáneos. En $E$ y $M 1$ todo el pasaje está puesto en boca de Lidoro, lo que no resulta muy afortunado. En $M 1$ una segunda mano interviene y reparte los versos entre Laura y Clori, como sucede en $M 2$. 
En este pasaje $V T$ y $M 2$ conservan de nuevo un verso (el mismo) perdido en $E$ y $M 1$ por manifiesto error. En $M 1$ intervienen dos segundas manos distintas: la primera añade me ausente para dar un poco de sentido al pasaje tal y como estaba. Pero otra mano diferente detecta la laguna y añade un verso que no coincide con el de $V T$ y $M 2$, por lo que presumiblemente lo haya hecho ope ingenii ${ }^{47}$.

Para complicar más las cosas, en ocasiones es $M 2$ el que tiene lagunas o errores comunes con $E$ no presentes ni en $V T$ ni en $M 1$ :

$V T / M 1$

a las aves, y podría

ser que, como os escuchase

(p. 56a; fol. 14v; vv. 739-740)

siendo así, no desconfíes, que tu hermosura y tu gracia

-y más si es que alguna vez.

donde ella lo escuche $e^{48}$ cantas-

podrá ser que la enamores

(p. 61a; fol. 21r; vv. 1127-1131)

ClORI ...y viendo al joven caer...

LAURA ...y desmayada la dama...

ClORI ...carga en los brazos con él. ${ }^{49}$

LAURA ...con ella carga en los brazos. ${ }^{50}$

LAS DOS Y ambos llegan a tus pies.

(p. 66a; fol. 28v-29r; vv. 1504-1508)

\section{E / M2}

a las aves, y podría ser

que, como os escuchase

(p. 9a; fol. 15r)

siendo así, no desconfíes,

que tu hermosura y tu gracia

[...]

$[\ldots]$

podrá ser que la enamores ${ }^{51}$

(p. 13a; fol. 22v)

ClORI ...y viendo al joven caer..

LAURA ...y desmayada la dama...

[...]

CLORI $^{52}$...ambos llegan a tus pies.

(p. 17b; fol. 31v)

En el primer pasaje citado se observa que $E$ y $M 2$ no distribuyen bien los versos, lo que genera una hipermetría y una hipometría. Es un fenómeno en el que coinciden ambos testimonios con frecuencia. En el segundo caso, VT y $M I$ cuentan con dos versos en un romance suprimidos en $E$ y $M 2$, y algo similar sucede en el tercero, aunque en él tenemos hasta tres estadios: dos versos de un romance de $V T$ se pierden en $E$ y $M 2$; en $M 1$ solo se suprime uno de ellos, lo que genera una irregularidad métrica; por ello, otra mano tacha este verso para que el romance quede bien métricamente. Es probable que en algún estadio

\footnotetext{
${ }^{47}$ Es la misma mano que, tras el verso $3446 b$, añade otros dos versos, en ese caso sí coincidentes con dos solo presentes en $M 2$.

${ }^{48}$ lo escuche: en $M 1$ parece que una segunda mano quiso corregir en te escuche.

49 carga en los brazos con él] om. M1

${ }^{50}$ con ella carga en los brazos] En M1 atribuido a CLORI.

51 enamores EVT M1 : enamoren M2. El sujeto es tu hermosura y tu gracia, por lo que la lectura correcta es la de $M 2$, enamoren.

${ }^{52}$ CLORI $M 2$ : LAURA $E$
} 
posterior ya no se haya copiado el verso tachado, lo que explicaría la laguna de los dos versos en $E$ y $M 2$.

En suma, puede irse observando cómo las combinaciones son complejas y no predecibles entre los diferentes testimonios, pero parece que $V T$ siempre queda bien parado, aunque resulte difícil saber en qué medida sus buenas lecturas se deben al testimonio en el que se basaba, o bien a la intervención del propio Vera. Sin embargo, $V T$ tampoco está libre de errores. Ya en un pasaje anterior se vio cómo coincidía con $E$ y $M 1$ en la lectura incorrecta enamores, lugar en el que solo $M 2$ presentaba la correcta enamoren. En los siguientes pasajes, también parece que la lectura buena es la de $M 2$, frente a la errónea o más discutible de los demás testimonios:

$V T$ / $E$ / $M 1$

dejo que me favorezca, obligándome a que haga de la infamia conveniencia, de que otro ${ }^{53}$ con mi nombre y mi estado la pretenda; y voy a qué fin tendrá una plática ${ }^{54}$ tan nueva (p. 77b; p. 28b; vv. 2381-2387)

Yo pienso que no ignoráis muchas quejas que de vos tengo, y en ellas quisiera que en secreta parte fuera, menos pública a los dos. ${ }^{55}$ (p. 81b; pp. 31b-32a; fol. 53v; vv. 2657-2661)
$M 2$

dejo que me favorezca, obligándome a que haga de la infamia conveniencia, dejo que otro con mi nombre y mi estado la pretenda; y voy a qué fin tendrá una novela tan nueva (fol. 55v)

Yo pienso que no ignoráis muchas quejas que de vos tengo, y en ellas quisiera hablar en parte que fuera, menos pública a los dos. (fol. 62v; vv. 2657-2661)

En el primer pasaje, la lectura correcta parece ser la de $M 2$, dejo, corrompida por probable mala copia en de lo, sin que el de de $V T$ tenga mayor sentido. En el siguiente, la presencia de hablar en $M 2$ hace preferible su lectura, pues su ausencia deja el texto con poco sentido ${ }^{56}$.

\footnotetext{
${ }^{53}$ de que otro $V T$ : de lo que otro E M1. Una segunda mano parece haber corregido en MI de lo en dejo, según $M 2$.

${ }^{54} \mathrm{M} 1$ lee primero plática, que se corrige en novela.

55 que en secreta parte fuera / menos pública a los $E V T$ : en parte que fuera menos pública a los [dos] M1. M1 fusiona los dos versos; una segunda mano añade hablar antes de en parte, para completar dos versos.

56 Otros errores comunes de VT E MI pueden verse en los versos 2666-2670, atribuidos todos ellos con poco sentido a Federico, o en el 3457, “Muera una aleve!”, frente al correcto “Muera un aleve" de $M 2$, pues aunque el verso lo pronuncia Federico dirigiéndose a Lisarda, él cree que va a apuñalar a un hombre enmascarado. Así lo entendieron también Hartzenbusch (Calderón de la Barca, 1849: 300b) y una segunda mano en $M 1$, que corrigieron en $u n$.
} 
En otros casos, $V T$ y $E$ comparten error, o presentan lecturas muy cercanas más bien erróneas, frente a los manuscritos, que ofrecen la lección buena:

$V T / E$

que, aunque mi silencio quiso

al hacer de la fineza, ${ }^{57}$

añadiéndola el callarla

al realce del hacerla,

(p. 72b; pp. 23b-24a; vv. 1996-1999)

Pero aquí está Federico;

nadie de mi mal sospeche.

(p. 98b; p. 47b; vv. 3928-3929)
M1 / M2

que, aunque mi silencio quiso

gala hacer de la fineza,

añadiéndola el callarla

por guarnición del hacerla,

(fol. 39v; fol. 45r)

Pero aquí está Serafina; nada de mi mal sospeche.

(fol. 78r; fol. $88 \mathrm{v})^{58}$

En algún caso, $M 1$ y $M 2$ contienen versos no presentes en $V T$ y $E$, por lo que quizá falten en estos últimos testimonios por error. Así puede suceder en el siguiente pasaje:

\section{$V T / E$}

CÉSAR ¿No dije que hasta que vengue tus enojos no le había de dejar [el traje]? Pues si se ofrece, ${ }^{59}$ verás en aqueste acero...

SERAFINA Locuras impertinentes; éntrate allá.

(p. 99a; p. 48a; vv. 3985-3990)
M1 / M2

CÉSAR ¿No dije que hasta que vengue tus enojos no le había de dejar [el traje]? Por si se ofrecen, verás en qué aqueste acero que de burlas ceñi emplee.

SERAFINA También dije yo que eran locuras impertinentes; éntrate allá.

(fol. 79r-v; fol. 89v)

Difícil resulta saber si son versos originales perdidos por error en $V T$ y $E$, o bien si se añadieron en algún momento por no entenderse bien el pasaje ${ }^{60}$.

En otros lugares son $V T, E$ y $M 2$ los que comparten error frente a $M 1$ :

57 Dada la falta de sentido de la lectura de VT, Hartzenbusch enmendó en "recatarte la fineza” (Calderón de la Barca, 1849: 290b).

${ }^{58}$ La lectura Federico es más bien un error, ya que el personaje está escondido, por lo que difícilmente Enrique, que es quien habla y acaba de entrar en escena, le habrá visto. En los versos siguientes, además, Laura se dirige a Serafina, y le dice: "Él [Enrique], viendo que aquí te estabas, / atento la espalda vuelve" (vv. 3930-3931), lo que confirma que la lección correcta en el v. 3928 es Serafina. También la lectura nada parece mejor que nadie, ya que es Serafina la que no debería sospechar nada. Otros errores comunes de $E$ y $V T$ pueden verse en los versos 2862, 3117 y 3851.

${ }^{59}$ Pues si se ofrece $V T$ : por si se ofrecen $E$, que coincide con M1 M2

${ }^{60} M 1$ y $M 2$ añaden otros dos versos tras el 2424 , pero no tienen sentido y parecen resultado de la corrupción de ese pasaje. 
$V T$ / E / M2

Que en mi ciega confusión

se verifican que son

hidras cortadas los celos,

(p. 80a; p. 30b; fol. 60r; vv. 2563-2565)

No vi la hora en ${ }^{61}$ que me viese, ya que este lance embaraza

en salir en la comedia, ${ }^{62}$

en este traje

(p. 93b; p. 43a; vv. 3568-3571)
M1

Que en mi ciega confusión

se verifica que son

hidras cortadas los celos,

(fol. 51v)

No vi la hora que me viese, ya que este lance embaraza el salir en la comedia, en este traje

(fol. 71r)

En el primer ejemplo, el sujeto es la cláusula "que son hidras cortadas los celos", por lo que la lectura correcta es verifica, según lee $M 1$ y como también corrigió Hartzenbusch (Calderón de la Barca, 1849: 294a). En el segundo, en salir es un error, pues se trata del complemento directo de embaraza, por lo que más correcto es el salir, según lee $M 1$ y enmienda Hartzenbusch (Calderón de la Barca, 1849: 301a). La lectura de $E, V T$ y $M 2$ parece un error común por atracción de "en este traje", del verso siguiente. El pasaje es un aparte que pronuncia César, que gran parte de la comedia ha estado disfrazado como Celia, y que por fin puede volver a aparecer como hombre.

Como se ha ido apreciando, $E$ suele estar implicado en la mayor parte de los errores a los que se ha pasado revista. Sus malas lecturas son incontables, y están presentes ya desde el principio de la comedia (vv. 1, 2, 8); se trata de deficiencias métricas (vv. 1699-1701, 1891, 1958, 1977, 2056, $2509,2519 \ldots$ ), faltas de sentido (vv. 1271, 1604, 1743...), nombres propios (vv. 53, 154, 353, 3249...) o incluso de elementos clave de la comedia, como los que se refieren al sexo de los personajes, lo que denota que en $E$ no se entendió bien el texto ${ }^{63}$.

Gran parte de estos errores están solo presentes en $E$; otros son comunes a uno o más de los otros testigos, como se ha ido viendo. Particularmente interesantes son aquellos casos en los que, ante errores de $E$, los demás testimonios difieren. Se han visto ya algunas discrepancias de $V T$ y $M 2$ ante errores comunes de $E$ y $M 1$; los siguientes ejemplos recogen diferencias entre $V T$, por un lado, y $M 1$ (ya de su primera mano) y $M 2$, por otro, ante errores de $E$ :

\footnotetext{
${ }^{61}$ en $V T:$ om. $E M 2$, que coinciden con $M 1$.

62 en la comedia $E M 2$ : de la comedia $V T$.

${ }^{63}$ Durante gran parte de la pieza Lisarda está disfrazada de hombre, con el nombre de César, y César está disfrazado de mujer, con el de Celia, de tal manera que en muchas ocasiones, aunque el nombre del locutor sea Lisarda, el texto está escrito en masculino, y, aunque el locutor sea César, en femenino. Sin embargo, en $E$ se producen no pocas alteraciones (vv. 2043, 2077, 2523, 2751), no presentes en los otros testimonios.
} 
$V T$

[Cés.] y no sé cómo

en un corazón se avenga el gusto y pesar a un tiempo.

Ser. Pues ¿qué es lo que sien[tes, Celia, que a tanto dolor te obliga? Cés. ¿Qué es lo que quieres [que sienta?

(p. 69a; vv. 1731-1736)

Cés. ¿Quién quieres que sea, [señora,

quien le llegase a escribir

si no quien más sabe amar y quien más sabe sentir?

Car. Bien disculpándome va

sin nombrarme y con sutil

y bien fundada razón.

Fed. Hoy es mi suerte feliz.

(p. 84ab; vv. 2880-2887)
E

[Cés.] y no sé cómo en un corazón se avengan [...] fantasías que atormentan. Ser. Pues ¿qué es, Celia, lo [que hoy sientes?

Cés. ¿Qué quieres que sienta? (p. 20b)

Cés. ¿Quién quieres que sea, [señora,

[...]

si no quien más sabe amar y quien más sabe sentir?

Car. Bien disculpándome va. Cés. Sin nombrarme y en sutil [...]

Fed. Enemiga de amor oí. (p. 34b)
M1 / M2

[Cés.] y no sé cómo en un corazón se avengan entre cláusulas que halagan fantasías que atormentan. Ser. Pues ¿qué es, Celia, lo [que hoy sientes?

Cés. ¿Qué quieres que sienta? (fol. 34r; fol. 38r.v)

Cés. ¿Quién quieres que sea, [señora,

quien llega a esplicarse asi ${ }^{64}$ si no quien más sabe amar y quien más sabe sentir...

Car. Bien disculpándome va sin nombrarme.

Cés. ${ }^{65}$...y en sutil enigma de amor pretende 66 decir y callar el fin de su pena en este estilo? Fed. Enigma de amor oú. (fols. 57v-58r; fol. 68v)

En el primer caso la ausencia de un verso en $E$ rompe el romance. $M 1$ y $M 2$ coinciden con el texto de $E$, y cuentan con el verso presumiblemente perdido en este; en $V T$ el romance está también completo, pero las diferencias son mayores, pues cambian por completo otros versos con respecto al texto de $E$, $M 1$ y $M 2$. El pasaje siguiente nos ofrece, en muy pocos versos, diferentes posibilidades combinatorias. Así, ante la primera omisión de $E$, difieren $V T$ y $M I$ (ya en su primera mano) en el verso con el que la solventan, lo que de nuevo hace sospechar que uno de los dos versos, al menos, no es genuino. En este caso, $M 2$ comparte la laguna con $E$, y una segunda mano la soluciona añadiendo un verso de acuerdo con la versión veratassiana. Cuatro versos después se produce una nueva laguna en $E$, y aquí las diferencias son mayores, pues, donde en $V T$ existe un verso que solventa el problema, en $M 1$ y $M 2$ hay hasta tres; además, otro verso difiere por completo en ambas versiones, aunque de nuevo los manuscritos se acercan más a $E$, pues la lectura de este, "Enemiga de amor ố", parece corrupción del correcto "Enigma de amor oî".

En el siguiente lugar, las diferencias alcanzan a los cuatro testimonios:

${ }^{64}$ En $M 2$ se omitió también este verso, como en $E$. Una segunda mano lo recuperó de acuerdo con la versión de $V T$ : "quien le llegase a escribir".

${ }^{65}$ En $M 2$ estos versos están en boca de CARLOS.

${ }^{66}$ La palabra pretende parece haber sido añadida en $M 1$ por la segunda mano para completar el verso; "en sutil enigma de amor" había sido copiado en una sola línea. 
VT

¡Ea, ingenio caprichoso, haz que quede mi cuidado, si se enoja, desdichado, si no se enoja, dichoso!) (p. 82b; vv. 2761-2764)

M1

¡Ea, ingenioso capricho, haz que quede mi cuidado, si dél se enoja, callado, si no se enoja, dicho[so]!) (fol. 55v)
E

¡Ea, ingenio caprichoso, haz que quede mi cuidado, [...], si no se enoja, dichoso!) (p. 33a)

M2

¡Ea, ingenio, ea, capricho, haz que quede mi cuidado, si se enojare, callado, y si no se enoja, dicho[so]!) (fol. 65v)

En este pasaje, de nuevo ante una omisión de $E$ difieren los demás testimonios, aunque es evidente la mayor cercanía de $M 1$ y $M 2$, que incluso comparten el extraño error dicho para rimar con capricho; frente a ellos, las lecturas de $V T$ parecen aquí más solventes ${ }^{67}$.

Esta cierta singularidad de $E$ que vamos apreciando no viene siempre de sus errores o lagunas; en otros pasajes se aleja de $V T, M 1$ y $M 2$ en versos enteros, aunque las lecciones pueden considerarse equipolentes:

$V T / M 1 / M 2$

Con ella cargué en los brazos $\mathrm{y}$, Eneas de amor, rompiendo canceles de fuego y humo salí al primer patio a tiempo (p. 53b; fol. 10v; fol. 11r; vv. 547-550)

Solo fue

este el necio ${ }^{68}$ que faltaba

para cansarme también ${ }^{69}$

(p. 64b; fol. 26v; fol. 28v; vv. 1394-1396)

\begin{abstract}
E
Con ella cargué en los brazos

$\mathrm{y}$, Eneas de amor rompiendo, saquela del fuego y vine hacia el primer patio a tiempo ${ }^{70}$ (p. 7a)
\end{abstract}

Solo fue este necio el que faltaba; nada me sucede bien (p. 16ab)

Los problemas textuales de la comedia deben de remontarse, así, bastante atrás, a arquetipos y subarquetipos desde los que los diferentes errores fueron

67 Otro lugar en el que difieren los cuatro testimonios es el verso 2891. De nuevo la peor lectura es la de $E$, la única que no encaja en el pasaje; el problema está en saber si alguno de los otros testimonios cuenta con la lectura genuina, o bien son todos intentos de corregir un error previo.

68 el necio $V T$ : necio el $M 1$ (que coincide con E); el loco $M 2$

${ }^{69}$ En $M 1$ el verso ha sido reforzado y es difícil leer la primera versión, que en todo caso empezaba por para

${ }^{70}$ Quizá la lectura de E nazca de una trivialización de canceles, que se transforma en saquela, lo que ocasionaría los demás cambios. 
pasando a los testimonios, aunque en estadios intermedios algunos pudiesen ser corregidos, bien ope ingenii, bien con otro testimonio a la vista, lo que explica las diferentes combinaciones que hemos ido analizando. Pero contamos también al menos con un error común a todos los testimonios:

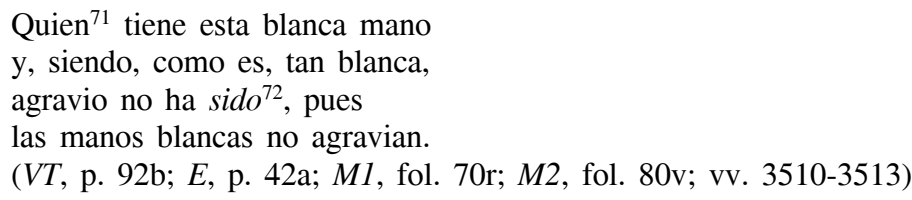

El pasaje queda un poco oscuro sintácticamente en todas las versiones. Hartzenbusch enmienda el verso 3510 y edita: "Sabed que... tiene esta mano" (Calderón de la Barca, 1849: 300c), lo que no mejora mucho las cosas. Quizá podría enmendarse sido en el v. 3512 y editar hecho: "agravio no ha hecho, pues".

Se aprecia, en suma, que las relaciones entre los cuatro testimonios principales son complejas, e imposibles de reducir a un stemma cabal. En ocasiones existe la tentación de atribuir las discrepancias entre $V T$, por un lado, y $M 1$ y/o $M 2$, por otro, ante errores y lagunas de $E$ a que quizá Vera quisiese solucionar los problemas de su texto base. Pero cabe recordar que la versión de $M 1$ y $M 2$ suele acercarse más en estos lugares a la de $E$, y sobre todo que la de $V T$ es decenas de versos más larga que la de los otros testimonios, por lo que Vera, indudablemente, se basaba en un texto más completo que $E, M 1$ o $M 2$, aunque contase a su vez con deficiencias difíciles de conocer, dada la tendencia de Vera a corregir y manipular sus textos base. Tal situación invita a la prudencia, y nos conduce al problema de las variantes propias de la manera de trabajar de Vera. En los casos en los que VT coincide con alguno de los otros testimonios, podemos tener la certeza de que Vera no estaba interviniendo; sin embargo, cuando se trata de lecturas singulares, surge la duda de saber en qué medida algunas lecciones de $E, M 1$ y $M 2$ son genuinas y las de $V T$ variantes típicas del amigo de Calderón, o bien son las de Vera las auténticas y las de E M1 M2 alteraciones debidas a la transmisión, si es que no puede darse el caso de que estemos ante variantes de autor.

Intervenciones propias de la labor editorial de Vera son algunos casos de modernizaciones gramaticales:

v. 394 trujo $E M 1 M 2:$ trajo $V T^{73} \quad$ v. 158 aqueste $E M 1 M 2:$ aquel $V T$ v. 1566 cay $E M 1 M 2$ : cae $V T \quad$ v. 922 propietaria $E M 1 M 2$ : proprietaria $V T^{74}$ v. 1717 y infeliz $E M 1 M 2$ : e infeliz $V T^{75}$

${ }^{71}$ Quien $V T M 1 M 2:$ que $E$

72 sido E M1 VT : abido M2 (parece omitirse un ha). La segunda mano de M1 intenta introducir una corrección, que parece ser abido, como en $M 2$.

${ }^{73}$ De nuevo en el v. 612. En el 842, sin embargo, M2 también lee trajo.

${ }^{74}$ Un caso análogo en el v. 1812.

${ }^{75}$ El uso de $y$ ante palabra iniciada por i- es rasgo habitual de los autógrafos de Calderón. 
En otros lugares se producen alteraciones del orden sintáctico que podrían también deberse a Vera, pues son uno de los rasgos típicos de su manera de $\operatorname{actuar}^{76}$ :

E / $M 1 / M 2$

y así el bien y el mal se vienen (p. 5a; fol. 7v; fol. 7v)

Antes bien viene la traza (p. $14 \mathrm{a}$; fol. $22 \mathrm{v}$; fol. $24 \mathrm{r}$ )
$V T$

y así el mal y el bien se vienen

(p. 51a; v. 367)

Antes viene bien la traza

(p. 61b; v. 1186) ${ }^{77}$

En otros pasajes nos encontramos con complejos casos de selección léxica que quizá se deban también a los hábitos de Vera antes que a errores de transmisión:

\section{E / M1 / M2}

Responde, porque no piense de nuestro secreto nada.

(p. 14a; fol. 22r; fol. 23v)

Dígalo el ver que, topando

en el correo una carta
$V T$

Responde, porque no entienda de nuestro secreto nada. (p. 61b; vv. 1181-1182) ${ }^{78}$

Dígalo el que habiendo hallado en la estafeta una carta

76 Véanse los abundantes ejemplos que recoge Hesse (1941: 98-111).

77 Otros ejemplos en vv. 537-538, 1329, 1425, 2162. También son dudosos los casos que se refieren al sintagma que da título a la comedia: "las manos blancas no ofenden" (o "no agravian"), aunque en este caso las diferencias atañen a los cuatro testimonios. Así, en los versos 3535, 3601 y 4157 lee VT "las manos blancas no agravian" ("no ofenden" en el 4157), frente a E M1 M2, que tienen "las blancas manos". En los versos 3513 y 3591 es M1 el que se queda solo, pues en ellos $V T, E$ y $M 2$ leen "manos blancas", mientras que $M 1$ sigue leyendo "blancas manos"; y, por último, en los versos 4313 y 4340-4341 coinciden los cuatro testimonios en "blancas manos". Así, M1 presenta siempre ese orden, "blancas manos", mientras que VT lee cinco veces "manos blancas" por dos de "blancas manos" y $E$ y $M 2$ cinco veces "blancas manos" por dos de "manos blancas". Resulta difícil explicar estas diferencias. En el caso de $M 1$, el completo dominio de una de las combinaciones está en consonancia con el propio título que tiene la comedia en este manuscrito: Blancas manos no agravian, en el que se modifican no solo el orden de "manos blancas", sino también el propio verbo, que, por otra parte, es el predominante en el texto de los cuatro testimonios, que en este caso sí coinciden en la presencia mayoritaria de agravian frente a ofenden. Cabe señalar también, sin embargo, que tanto la lista de Carlos II o Marañón como la de Veragua coinciden en dar a la comedia el título Manos blancas no ofenden. ¿Sería el de $M 1$ el título original, que, por las razones que fuesen, se cambió en algún momento? En todo caso, sí parece que, al menos en lo que respecta a las recurrencias del título, o de fórmulas parecidas, $M 1$ ocupa un extremo y $V T$ el otro, con $E$ y $M 2$ en una extraña posición intermedia. De nuevo es difícil también saber si habrá sido $V T$ el que introdujo variaciones en los versos señalados para adecuarlos al título con el que le llegó la comedia, o si ya estaba así en el texto en el que basó su edición.

${ }^{78}$ Hesse (1941: 10-11) recopila diferentes ejemplos en que Vera sustituye formas de pensar por otras del verbo entender. 
con su nombre, supe della que su padre la avisaba que estaba aquí (p. 40a; fol. 67r; fol. 77v) con su nombre, supe della que su padre la avisaba que estaba aquí (p. 90b; vv. 3342-3346)

El ejemplo más interesante es el segundo: por un lado, podemos estar prácticamente seguros de que Calderón utilizó el verbo topar, que a Vera Tassis no le gustaba, por lo que lo cambiaba sistemáticamente por hallar o encontrar ${ }^{79}$; pero, por otro, en lo que se refiere a la variante correo-estafeta, es posible que la lectura correo sea una lectio facilior de E M1 M2, ya que estafeta aparece en cinco comedias de Calderón, incluida la autógrafa La desdicha de la voz (v. 1256). Además, parece haber ciertas diferencias de significado entre correo (más bien la persona, aunque no solo) y estafeta, que quizá hagan preferible esta última lectura, aunque la diferencia no es grande.

Todo esto nos conduce al problema de qué texto utilizó Vera Tassis para su edición de la comedia, cuestión que ha preocupado en los últimos años a algunos estudiosos y en la que puede no ser baladí el hecho de que esté encabezada por el membrete "Fiesta que se representó a sus majestades en el salón de su real palacio". Según quedó atestiguado por un documento relativo a una representación en palacio de Ni Amor se libra de amor (o Psiquis y Cupido) en 1679, Calderón participaba en estas representaciones palaciegas revisando tex$\operatorname{tos}^{80}$, y estudiosos como Shergold (1955) o Erik Coenen (2006, 2008, 2011a y 2011b) han apuntado la posibilidad de que las variantes de algunas ediciones de Vera Tassis, particularmente las que llevan el mencionado membrete o alguna de sus variantes (como es el caso de Las manos blancas), se deban, no tanto al ingenio del amigo de Calderón, como a que Vera hubiese tenido acceso a manuscritos utilizados en esas representaciones palaciegas y que recogiesen variantes que podrían deberse al propio poeta.

En lo que respecta a nuestra comedia, el DICAT documenta una representación en el Palacio Real de Madrid el 21 de septiembre de 1680 a cargo de la compañía de Jerónimo García, con loa y sainetes, para celebrar el cumpleaños del duque de Orleans, "padre de la reina nuestra señora reinante" (DICAT, s. v. "García, Jerónimo, apodado Tocanovias", año 1680), por lo que el paratexto que añadió Vera en su edición quizá se refiriese a este montaje, o bien a alguno similar del que no haya quedado constancia documental ${ }^{81}$. Calderón aún vivía

\footnotetext{
79 Pueden verse los abundantes ejemplos que recoge Hesse (1941: 1-4).

${ }^{80}$ Así, en esa ocasión se le pagaron 200 ducados "por la loa y por haber enmendado el texto" (Coenen, 2011a: 987).

${ }^{81}$ Sí se documentan otras puestas en escena en palacio en 1693, 1694, 1695 y 1697, siempre en el alcázar de Madrid. Los datos los tomo del DICAT; la comedia carece aún de registro en CATCOM.
} 
entonces, por lo que bien pudo haber tomado parte en la preparación de esta puesta en escena y revisar el texto, como consta que al menos sucedió en la mencionada de Ni Amor se libra de amor. Así, no cabe descartar la hipótesis de que haya sido el texto empleado en alguno de estos montajes palaciegos de finales de siglo, acaso revisado por Calderón, el que llegó a manos de Vera mientras preparaba la Octava parte. En ese caso, está claro que ese texto no se habría basado en $E, M 1$ ni $M 2$, pues contendría los versos no presentes en estas, y diferiría de la versión "corta" en una medida difícil de ponderar con los datos a nuestro alcance ${ }^{82}$.

Así, pues, de haberse producido esta revisión tardía, la edición de Vera Tassis, además de corresponderse en parte con un texto más cercano al salido originalmente de la pluma de Calderón que el de E M1 M2, podría incluir innovaciones introducidas en la comedia con motivo de alguna de esas representaciones palaciegas, de tal manera que $V T$ representaría una suerte de tercera versión de la comedia. Podría hablarse entonces de: a) una primera versión de Las manos blancas no ofenden, escrita en 1640 y hoy perdida, pero que debía de contener los versos presentes en $V T$ y no en $E M 1 M 2$, pues parecen faltar de estos testimonios, o bien por error, o bien para aligerar la larguísima primera jornada; b) de una segunda versión representada por $M 1, M 2^{83}$ y $E$, texto recortado por un autor de comedias y posteriormente deturpado, al menos a su llegada a la imprenta; y c) de una tercera versión, el texto de $V T$, que se correspondería con el utilizado en alguna puesta en escena tardía de la comedia. Tal texto se habría basado en uno no descendiente de $E M 1 M 2$, sino más bien de esa primera versión perdida, por contener los versos ausentes de $E M 1 M 2$, al tiempo que incluiría diferentes variantes y retoques quizá atribuibles a una revisión del texto llevada a cabo por alguien, tal vez el propio Calderón, con motivo de esa representación palaciega.

También cabría la posibilidad, ya apuntada, de que el de Vera se acerque al texto original de la comedia, y que las divergencias con E M1 M2 - tanto los errores y lagunas como los cortes y las variantes equipolentes, incluido el más dudoso caso de los versos de Fabio ya analizados - se deban a errores en la

${ }^{82}$ El propio Coenen (2011a: 988) sugiere la posibilidad de que las variantes del texto de Vera Tassis de Las manos blancas no ofenden con respecto al de Escogidas se deban a una intervención de Calderón en una representación palaciega tardía, como él defiende que pudo haber sucedido con Amar después de la muerte, Amado y aborrecido y Darlo todo y no dar nada. El estudioso holandés considera, en las comedias analizadas por él, que esas representaciones palaciegas utilizaban el texto de alguna edición anterior, normalmente de la colección de Escogidas, que era enmendado en mayor o menor grado; en el caso de Las manos blancas, sin embargo, no parece que haya podido ser el texto de Escogidas el empleado en una supuesta puesta en escena palaciega, dadas las lagunas que presenta con respecto al de Vera, como ya se analizó.

${ }^{83}$ Como se vio en su momento, en algunos pasajes $M 2$ parece constituir un estadio intermedio entre $V T$ y $E M 1$. 
transmisión de esta rama y a intervenciones de un autor de comedias. Aunque en contra de esta hipótesis operan algunas variantes, ya analizadas, en las que el texto de los otros testimonios, particularmente $M 1 M 2$, parece preferible, o aquellas en las que quizá Vera estuviese corrigiendo lagunas y defectos de su texto base.

La situación que sí parece descartable es la de que la rama de E M1 M2 se corresponda con el texto original, muy deturpado en el caso de $E$, y $V T$ con una revisión a conciencia de ese texto realizada por Calderón, que lo habría ampliado además en varias decenas de versos no particularmente relevantes. Es decir, considero que no puede defenderse que $E M 1 M 2$, por un lado, y $V T$, por otro, representen dos versiones autoriales de Las manos blancas no ofenden que deban recibir igual atención por parte de un editor e incluso publicarse de manera independiente; antes bien, el tipo de diferencias entre las dos ramas invita a pensar en la intervención de —al menos- un autor de comedias con la intención de recortar el texto, a lo que se unieron diferentes corrupciones e intervenciones achacables a la transmisión. Así, probablemente solo haya existido una versión de la comedia, representada a grandes rasgos por $V T$ (con diferentes malas lecturas debidas a la transmisión, así como con probables intervenciones del editor), recortada en $M 1$ y $M 2$ y deturpada sobremanera en $E$. De haber existido revisión por parte de Calderón (si se acepta que intervino en alguna representación palaciega tardía y que esas modificaciones pasaron al texto de $V T$ ), las variantes de autor no irían más allá de muy pocos versos, y probablemente también puedan ser atribuibles a la intervención de otros factores ajenos al poeta, aunque en todo caso seguirían haciendo de $V T$ el testimonio más autorizado.

De este modo, entiendo que la única posibilidad coherente de edición de Las manos blancas no ofenden consiste en tomar como texto base el de Vera Tassis, corregido en aquellos lugares en que las lecturas de los otros testimonios (en particular $M 1$ y M2) sean manifiestamente mejores, así como en aquellos otros en los que pueda sustentarse con cierta seguridad la hipótesis de que una determinada variante de Vera se debe al intervencionismo de este - bien porque estuviese corrigiendo un texto en mal estado; bien por su gusto personal-, y no a que esa lección se encontrase en el texto que seguía. En esta tarea, la carencia de rigurosos estudios sobre la lengua de Calderón basados exclusivamente en sus autógrafos nos impide todavía actuar de manera efectiva en muchos de estos casos de presumibles variantes veratassianas; por ello, ha de operarse con suma prudencia a la hora de enmendar una lectura de VT partiendo de E M1 M2 en la creencia de que es esta la lección genuina de Calderón y la otra una innovación de su ilustre editor sustentada en su gusto personal. Sí podremos estar más seguros de que una lectura es genuina cuando VT coincida con algún otro testimonio, aunque, como hubo ocasión de ver, en ocasiones parece tratarse de errores heredados de textos anteriores. 
En suma, Las manos blancas no ofenden es un buen ejemplo de las dudas y problemas que le surgen al editor a la hora de enfrentarse a una comedia conservada en testimonios que varían sensiblemente entre sí, pero ninguno de los cuales contó con la participación o la aprobación de Calderón, a lo que cabe sumar las enrevesadas relaciones entre ellos. Así, antes que hablar de dos versiones autoriales e independientes, debe apuntarse más bien que los cuatro testimonios han sufrido, en distinto grado, los avatares de la transmisión, al tiempo que el texto de $E M 1 M 2$ parece el resultado de la intervención de un autor de comedias que quiso recortar el texto de la extensa primera jornada, a lo que se unieron diferentes errores achacables a la transmisión y multiplicados en $E$. En consecuencia, solo cabe editar el texto publicado por Vera Tassis en la $O c$ tava parte de Calderón, el más completo y correcto, aunque resulta muy difícil decir si se remonta al original del poeta compuesto más de cuarenta años antes, o bien si incluye innovaciones introducidas, acaso por el propio Calderón, en alguna tardía representación palaciega. El texto de Vera, sin embargo, no está libre de errores ni de lecturas que parecen inferiores a las de otros testimonios, a lo que hay que sumar el problema de la fiabilidad de las ediciones del amigo de Calderón, agravado en este caso por desconocerse en qué texto basaba su edición. Por ello, habrá de acudirse en ocasiones al texto de E M1 M2 en la creencia de que pueden haber preservado lecciones genuinas de Calderón alteradas por Vera, o bien ya en el texto que este seguía y que quizá Vera no advirtió o incluso enmendó. En manos del iudicium del editor queda el grado de correcciones a las que habrá de someterse el texto veratassiano, según considere que sus lecturas, o bien reproducen lecciones erróneas de testimonios anteriores, o bien quizá estén corrigiendo un texto defectuoso, o bien son variantes recurrentes en la manera de editar del "amigo" de Calderón.

\section{BIBLIOGRAFÍA}

Antonucci, Fausta (2013): “A vueltas con la reescritura de Calderón: el caso de Judas Macabeo", Criticón, CXIX, pp. 235-248.

Antonucci, Fausta y Marc Vitse (1998): "Algunas observaciones acerca de las dos versiones de la tercera jornada de La dama duende", Criticón, LXXII, pp. 49-72.

Ashcom, B. B. (1973): “The Two Versions of Calderón's El conde Lucanor”, Hispanic Review, XLI, pp. 151-60.

Caamaño Rojo, María J. (2001): “El mayor monstruo del mundo” de Calderón de la Barca. Estudio textual, Santiago de Compostela, Universidade de Santiago de Compostela.

Caamaño Rojo, María J. (2002): "El mayor monstruo del mundo, de Calderón: reescritura y tradición textual”, Criticón, LXXXVI, pp. 139-157.

Calderón de la Barca, Pedro (1849): Las manos blancas no ofenden, en Comedias de don Pedro Calderón de la Barca, III, Juan Eugenio Hartzenbusch (ed.), Madrid, Rivadeneyra, pp. 279-306.

Calderón de la Barca, Pedro (1971): En la vida todo es verdad y todo mentira, Don W. Cruickshank (ed.), London, Tamesis. 
Calderón de la Barca, Pedro (1982): Cada uno para sí, José María Ruano de la Haza (ed.), Kassel, Reichenberger.

Calderón de la Barca, Pedro (1985): El mágico prodigioso, Bruce W. Wardropper (ed.), Madrid, Cátedra.

Calderón de la Barca, Pedro (1989): El agua mansa / Guárdate del agua mansa, Ignacio Arellano y Víctor García Ruiz (eds.), Kassel, Reichenberger.

Calderón de la Barca, Pedro (1995a): Basta callar, Daniel Altamiranda (ed.), Kassel, Reichenberger

Calderón de la Barca, Pedro (1995b): Las manos blancas no ofenden, Ángel Martínez Blasco (ed.), Kassel, Reichenberger.

Calderón de la Barca, Pedro (1999): El diablo mudo, Celsa Carmen García Valdés (ed.), Pamplona/ Kassel, Universidad de Navarra/Reichenberger.

Calderón de la Barca, Pedro (2000): Basta callar, Margaret R. Greer (ed.), Ottawa, Dovehouse Editions Canada.

Calderón de la Barca, Pedro (2003): La desdicha de la voz, T. R. A. Mason (ed.), Liverpool, Liverpool University Press.

Calderón de la Barca, Pedro (2007): Comedias, III. Tercera parte de comedias, Don W. Cruickshank (ed.), Madrid, Biblioteca Castro.

Calderón de la Barca, Pedro (2008): La vida es sueño, Fausta Antonucci (ed.), Barcelona, Crítica.

Calderón de la Barca, Pedro (2009): El mágico prodigioso, Natalia Fernández (ed.), Barcelona, Crítica.

Calderón de la Barca, Pedro (2011): El astrólogo fingido, Fernando Rodríguez-Gallego (ed.), Ma$\mathrm{drid} /$ Frankfurt am Main, Iberoamericana/Vervuert.

Calderón de la Barca, Pedro (2012): Judas Macabeo, Fernando Rodríguez-Gallego (ed.), Madrid/ Frankfurt am Main, Iberoamericana/Vervuert.

Calderón de la Barca, Pedro (2015a): La banda y la flor, Jéssica Castro Rivas (ed.), Madrid/Frankfurt am Main, Iberoamericana/Vervuert.

Calderón de la Barca, Pedro (2015b): El secreto a voces, Wolfram Aichinger, Simon Kroll y Fernando Rodríguez-Gallego (eds.), Kassel, Reichenberger.

Calderón de la Barca, Pedro (2015c): La señora y la criada y El acaso y el error: dos comedias palatinas, Covadonga Romero Blázquez (ed.), Newark (Delaware), Juan de la Cuesta.

Calderón de la Barca, Pedro (2017): El mayor monstruo del mundo y el mayor monstruo los celos, María J. Caamaño (ed.), Madrid/Frankfurt am Main, Iberoamericana/Vervuert.

Casais Vila, Verónica (2014): "Dos versiones de la primera jornada de Las manos blancas no ofenden de Calderón de la Barca”, en Carlos Mata Induráin, Adrián J. Sáez y Ana Zúñiga Lacruz (eds.), "Sapere aude". Actas del III Congreso Internacional Jóvenes Investigadores Siglo de Oro (JISO 2013), colección BIADIG, Pamplona, Universidad de Navarra, pp. 45-57.

Casariego Castiñeira, Paula (2015): "Procesos de composición en los folios autógrafos de Cada uno para sî", Anuario calderoniano, VIII (Número monográfico: Calderón en su laboratorio, ed. por Wolfram Aichinger y Simon Kroll), pp. 53-70.

Coenen, Erik (2006): "Juan de Vera Tassis, editor de Calderón: el caso de Amar después de la muerte", Revista de Filología Española, LXXXVI, 2, pp. 245-257.

Coenen, Erik (2008): "Sobre el texto de Darlo todo y no dar nada y la transmisión textual de las comedias de Calderón”, Criticón, CII, pp. 195-209.

Coenen, Erik (2011a): "Del libro al palacio, del palacio al libro. Una hipótesis sobre la transmisión textual de las comedias de Calderón", en Antonio Azaustre Galiana y Santiago Fernández Mosquera (coords.), Compostella Aurea, actas del VIII Congreso de la AISO. Santiago de Compostela, 7-11 de julio de 2008, Santiago de Compostela, Universidade de Santiago de Compostela, pp. 983-991.

Coenen, Erik (2011b): "La enigmática transmisión textual de Amado y aborrecido", Anuario calderoniano, IV, pp. 33-54.

Cruickshank, Don W. (1973): “The textual criticism of Calderón's comedias: a survey”, en Pedro Calderón de la Barca, The Textual Criticism of Calderón's, vol. I de Comedias, ed. facsímil a cargo de Don W. Cruickshank y John E. Varey, London, Tamesis, pp. 1-53. 
Cruickshank, Don W. (1983): "Don Juan de Vera Tassis y Villarroel”, en Karl-Hermann Körner y Dietrich Briesemeister (eds.), Aureum Saeculum Hispanum. Beiträge zu Texten des Siglo de Oro. Festschrift für Hans Flasche zum 70. Geburtstag, Wiesbaden, Franz Steiner, pp. 43-57.

Cruickshank, Don W. (2009): Don Pedro Calderón, Cambridge, Cambridge University Press.

DICAT = Diccionario biográfico de actores del teatro clásico español (2008), [DVD], Teresa Ferrer Valls (dir.), Kassel, Reichenberger.

Escudero, Juan Manuel (2009): "Problemas textuales de El escondido y la tapada de Pedro Calderón de la Barca", Anuario calderoniano, II, pp. 129-142.

Greer, Margaret Rich (1984): "Calderón, Copyists, and the Problem of Endings", Bulletin of the Comediantes, XXXVI, 1, pp. 71-81.

Hernando Morata, Isabel (2012): "En torno al texto de El príncipe constante, de Calderón: el manuscrito 15.159 de la BNE”, Boletín de la Biblioteca de Menéndez Pelayo, LXXXVIII, n. ${ }^{\circ}$ 2, pp. 197-234.

Hesse, Everett Wesley (1941): Vera Tassis' Text of Calderón's Plays (Parts I-IV), tesis de doctorado inédita, New York University.

Iglesias Feijoo, Luis y Alejandra Ulla Lorenzo (2011): "Los textos de El Faetonte de Calderón”, en Frederick de Armas y Luciano García Lorenzo (eds.), Calderón: del manuscrito a la imprenta, Madrid/Frankfurt am Main, Iberoamericana/Vervuert, pp. 29-51.

Kroll, Simon (2014): “¿Cuántas versiones ofrece un autógrafo? Las intervenciones de autor en el autógrafo de El secreto a voces", Hipogrifo, II.2, pp. 63-79.

Larrañaga Donézar, Maravillas (1989): "Introducción”, en Pedro Calderón de la Barca, El escondido y la tapada, Barcelona, PPU.

Manjarrez, Graciela (2007): "Transmisión textual de El Conde Lucanor, de Pedro Calderón de la Barca", en Lillian von der Walde et alii (eds.), "Injerto peregrino de bienes y grandezas admirables". Estudios de literatura y cultura española e hispanoamericana (siglos XVI al XVIII), México D. F., UAM, pp. 311-333.

Montarnal, Louis y Marc Vitse (1968): "Para una edición de El conde Lucanor, de Calderón de la Barca", Segismundo, VII-VIII, pp. 51-72.

Pedraza Jiménez, Felipe B. (2000): Calderón. Vida y teatro, Madrid, Alianza.

Rodríguez-Gallego, Fernando (2010): "Aproximación a la reescritura de comedias de Calderón de la Barca", en Natalia Fernández Rodríguez (ed.),"Como en la antigua, en la edad nuestra". Presencia de la tradición en la literatura española del Siglo de Oro, Barcelona, Prolope/Gráficas Celler, pp. 157-193.

Rodríguez-Gallego, Fernando (2013): "La labor editorial de Vera Tassis", Revista de Literatura, LXXV, 150, pp. 463-493.

Rodríguez-Gallego, Fernando (2015): "Sobre las ediciones de las Obras completas de Calderón de la Barca preparadas por Valbuena Briones", Arte nuevo: revista de estudios áureos, II, 2015, pp. 74-105.

Romero Blázquez, Covadonga (2007): Estudio, edición crítica y anotación de dos comedias palatinas de Calderón de la Barca: "La señora y la criada" y "El acaso y el error", tesis de doctorado dirigida por Ignacio Arellano, Pamplona, Universidad de Navarra.

Ruano de la Haza, José María (1998): "Las dos versiones de El mayor monstruo del mundo, de Calderón”, Criticón, LXXII, pp. 35-47.

Shergold, N. D. (1955): "Calderón and Vera Tassis”, Hispanic Review, XXII, pp. 212-218.

Suárez, Juan Luis y Graciela Manjarrez (2008): "La intención editorial de Calderón y la edición de las comedias de la Cuarta parte", Anuario calderoniano, I, pp. 317-332.

Vitse, Marc (1998): "Presentación", Criticón, LXXII (Número monográfico: Siglo de Oro y reescritura. I: Teatro, ed. por M. Vitse), pp. 5-10. 